\title{
Maus-tratos e discriminação na assistência ao aborto provocado: a percepção das mulheres em Teresina, Piauí, Brasil
}

\author{
Maltreatment and discrimination in induced abortion care: \\ perception of women in Teresina, State of Piauí, Brazil
}

\begin{abstract}
Alberto Pereira Madeiro ${ }^{1}$
Andréa Cronemberger Rufino ${ }^{1}$
\end{abstract}

${ }^{1}$ Centro de Ciências da Saúde, Universidade Estadual do Piauí. R. Olavo Bilac 2335, Centro. 64001280 Teresina PI Brasil. madeiro@uol.com.br

\begin{abstract}
Treatment of complications resulting from induced abortion may be hampered by discriminatory attitudes manifested by healthcare professionals in hospitals and abortion services. This article retrieved stories of institutional abuse directed at women who had an induced abortion in illegal and unsafe conditions. Seventy-eight women admitted to a public hospital in Teresina for complications after an induced abortion were interviewed. A semi-structured script was used with questions about practices and itineraries of abortion and institutional violence during hospitalization. Discriminatory practices and maltreatment during care were reported by 26 women, especially among those who confessed to induction of the abortion. Moral judgement, threat of filing a complaint to the police, negligence in the control of pain, long wait for uterine curettage, and hospitalization with mothers who have recently given birth were the main types of institutional violence reported by women. Cases of institutional violence in the care of induced abortion violates the duty of the healthcare service and prevents women from receiving the necessary health care.
\end{abstract}

Key words Induced abortion, Institutional violence, Abortion services, Maltreatment
Resumo $O$ tratamento das complicações do aborto provocado pode ser dificultado por atitudes de discriminação praticadas por profissionais de saúde nos hospitais e serviços de aborto. Este artigo recuperou histórias de violência institucional entre mulheres que provocaram o aborto em condições ilegais e inseguras. Foram entrevistadas 78 mulheres internadas em um hospital público de referência em Teresina por complicaçães do aborto provocado. Utilizou-se roteiro semiestruturado com perguntas sobre práticas e itinerários de aborto e violência institucional durante a internação. Práticas discriminatórias e de maus-tratos durante a assistência foram relatadas por 26 mulheres, principalmente entre aquelas que confessaram a indução do aborto. Julgamento moral, ameaças de denúncia à polícia, negligência no controle da dor, longa espera pela curetagem uterina e internação conjunta com puérperas foram os principais tipos de violência institucional narrados. As práticas de violência institucional na assistência ao aborto provocado violam o dever de acolhimento do serviço de saúde e impedem que as mulheres tenham suas necessidades de saúde atendidas.

Palavras-chave Aborto induzido, Violência institucional, Serviços de aborto, Maus-tratos 


\section{Introdução}

O aborto induzido de maneira insegura é um grave problema de saúde pública em países onde há restrição legal à interrupção da gravidez. Em 2008, uma em cada cinco gestações no mundo terminou em aborto, dos quais $49 \%$ foram inseguros $^{1}$. Estima-se que cinco milhões de mulheres sejam hospitalizadas por complicações decorrentes do aborto inseguro a cada ano ${ }^{2}$. O aborto é responsável por $13 \%$ das mortes entre mulheres grávidas, geralmente por hemorragia ou infecção ${ }^{1,3}$. São as mulheres abaixo de 20 anos, solteiras e com idade gestacional mais elevada as que apresentam maior risco de morte após o aborto inseguro ${ }^{4}$.

No Brasil, um inquérito nacional realizado em 2010 mostrou que $22 \%$ das mulheres entre 35 e 39 anos já tinham realizado aborto. Daquelas que relataram a prática, $55 \%$ necessitaram de internação hospitalar por complicações ${ }^{5}$. A introdução do misoprostol no cenário nacional mudou o padrão das complicações pós-aborto, diminuindo a frequência de casos graves de infecção, comuns até a década de $1980^{6}$. Apesar de o misoprostol ser considerado um método abortivo eficaz, mais barato e com menores riscos à saúde da mulher ${ }^{7}$, a curetagem uterina pós-aborto ainda é um dos procedimentos obstétricos mais realizados no país ${ }^{8}$.

Não se sabe se mulheres que abortam com o misoprostol têm maior frequência de internação hospitalar. Desde 1998, o uso da droga é restrito a hospitais credenciados e, assim, sua obtenção é feita no mercado clandestino de medicamentos, onde não há segurança sobre procedência, qualidade e doses ${ }^{9}$. A hipótese seria de que a obtenção do medicamento no comércio ilegal comprometeria a eficácia da substância e, como consequência, elevaria o número de abortos incompletos. De toda forma, os dados empíricos têm demonstrado que o itinerário mais comum no Brasil é a mulher iniciar o aborto em casa, com misoprostol, e finalizá-lo no hospital, onde é internada por aborto incompleto para realização da curetagem uterina ${ }^{10}$.

Mulheres que necessitam de tratamento por aborto incompleto esperam apoio, privacidade, confidencialidade e respeito durante seu atendimento. Entretanto, principalmente nos países onde o aborto não é permitido, muitas mulheres podem sofrer desrespeito e abusos nos serviços de saúde ${ }^{11}$. Termos como "violência obstétrica", "tratamento desumano" e "desrespeito e abuso" têm sido utilizados por autores e organizações diversas para caracterizar maus-tratos durante a assistência em saúde ${ }^{12}$. Embora não haja consenso sobre o melhor termo e conceito de violência institucional, há concordância que esse fenômeno causa sofrimento para a mulher, que influencia negativamente a qualidade do cuidado prestado e que atua como barreira para a utilização do serviço de saúde no futuro ${ }^{11-15}$. No Brasil, o Ministério da Saúde estabeleceu a definição de violência institucional como sendo "aquela exercida nos/pelos próprios serviços públicos, por ação ou omissão", englobando tanto atos praticados por profissionais durante a assistência como condições estruturais do sistema de saúde ${ }^{16}$. Em 2010, a Agência para Desenvolvimento Internacional dos Estados Unidos (USAID) sugeriu sete categorias amplas para mensurar a violência institucional: ausência de confidencialidade, cuidado clínico não consentido, violência física, negligência, detenção na instituição, cuidado não digno e discriminação. Desde então, esses critérios têm sido a referência para a avaliação de maus-tratos durante a assistência obstétrica ${ }^{11}$.

No contexto do aborto, são recorrentes as descrições de julgamento moral, adiamento da curetagem e, ainda, baixo controle da dor no cotidiano da assistência ${ }^{17}$. Um inquérito com amostra probabilística de 2.365 mulheres de áreas urbanas e rurais de todo o Brasil, realizado em 2010 , revelou que $53 \%$ daquelas que provocaram o aborto informaram ter sofrido algum tipo de violência durante a internação hospitalar. Entre essas mulheres, $17 \%$ delas disseram que foram ameaçadas pela equipe de saúde com possibilidade de denúncia à polícia ${ }^{18}$. Ainda em 2010, outra pesquisa com 2.804 mulheres avaliou a qualidade da atenção às pacientes admitidas por aborto em hospitais públicos de Salvador, Recife e São Luís. Um dos principais resultados foi que o cuidado em saúde ofertado estava em desacordo com as normas preconizadas pela legislação brasileira, além de o controle da dor ter sido frequentemente inadequado ${ }^{19}$.

A magnitude e o impacto da violência institucional na assistência às complicações do aborto provocado ainda são pouco conhecidos no Brasil. Os dados existentes são oriundos de estudos com amostra pequena, com avaliação conjunta do aborto espontâneo, ou ainda de pesquisas desenhadas especificamente para caracterizar a violência durante a assistência ao parto e puerpério $^{20-22}$. O presente artigo recupera histórias de violência institucional na assistência ao aborto provocado, sob a ótica das mulheres, em um hospital público de referência em Teresina, no Piauí. 


\section{Metodologia}

O estudo foi conduzido entre junho de 2012 e novembro de 2013, tendo como unidade de análise mulheres que realizaram aborto de maneira ilegal e insegura e estavam internadas em hospital público de referência em Teresina, Piauí, para realização de curetagem uterina por aborto incompleto. Foram excluídas da pesquisa mulheres que sofreram aborto espontâneo e todas aquelas menores de 18 anos. A pesquisa foi aprovada pelo Comitê de Ética em Pesquisa da Universidade Estadual do Piauí e também contou com carta de concordância da direção do hospital. O termo de consentimento livre e esclarecido das participantes foi obtido oralmente, com o objetivo de garantir o sigilo e o anonimato dos dados. O direito de não participar ou de interromper a entrevista a qualquer momento foi facultado às mulheres, sendo-lhes explicitado também que a participação não fazia parte do atendimento médico oferecido pelo hospital.

Diariamente, todas as mulheres internadas por aborto incompleto que já tivessem sido submetidas à curetagem uterina foram abordadas e questionadas sobre o interesse em participar da pesquisa. Aquelas que aceitaram o convite foram levadas a uma sala reservada, próxima à enfermaria, onde as entrevistas foram realizadas. Todas as entrevistas foram gravadas. Somente foram consideradas válidas as entrevistas daquelas que confirmaram ter induzido o aborto, sendo o critério de inclusão no estudo a narrativa de cada mulher e não indícios ou vestígios do medicamento abortivo encontrados pelo médico responsável pela curetagem e/ou registrados no prontuário. Nos casos em que houve discordância entre o registro do prontuário e a palavra da mulher, teve preponderância a narrativa desta. As transcrições foram realizadas fora do ambiente hospitalar, sem identificação das participantes. As gravações foram destruídas imediatamente após a transcrição de forma a eliminar qualquer registro material da conversa.

As entrevistas foram guiadas por roteiro semiestruturado que explorou duas questões centrais: 1. métodos e itinerários para abortar; 2 . atendimento prestado durante a internação hospitalar, com ênfase na possibilidade de violência institucional. As perguntas sobre práticas de aborto identificaram os métodos utilizados pelas mulheres para o induzir, tais como medicamentos, sondas uterinas, chás ou ervas. Com o objetivo de uniformização, o nome "misoprostol" foi usado para todas as vezes em que as mulheres se referiram à utilização de “Citotec ${ }^{\circledR ”}$ para abortar. O itinerário do aborto foi entendido como o percurso que a mulher percorreu para ter acesso às práticas e aos métodos, tais como onde comprou o medicamento, quem ofereceu o chá ou onde conseguiu recursos. A presença de violência institucional foi considerada quando a mulher respondeu "sim" a qualquer uma das perguntas que caracterizam as sete categorias da USAID (violência física, tratamento não digno, detenção na instituição, falta de confidencialidade, violação de privacidade, negligência ou, ainda, discriminação ${ }^{11}$. Para validação do instrumento de pesquisa, foram realizadas entrevistas com $10 \mathrm{mu}-$ lheres, que possibilitaram adequação na forma e na ordem das perguntas. As 10 entrevistas iniciais (pré-teste) não foram contabilizadas no universo dos dados tabulados.

As entrevistas foram realizadas e transcritas por dois pesquisadores médicos, um homem e uma mulher, não pertencentes à instituição onde a pesquisa foi desenvolvida e sem nenhuma relação de assistência durante a internação (realização da curetagem, prescrição de medicamentos ou alta hospitalar). Para a análise, todas as entrevistas foram lidas de forma pormenorizada e, em seguida, codificadas pelos dois pesquisadores de maneira independente. Os dados foram tabulados com base em um instrumento com 15 perguntas sobre os métodos, o itinerário e, principalmente, as histórias de violência institucional. Os pesquisadores compararam os padrões encontrados e, quando discrepantes, revisaram as transcrições.

\section{Resultados e discussão}

\section{Perfil das mulheres}

Durante o estudo, 78 mulheres foram entrevistadas e todas foram submetidas à curetagem como método de esvaziamento uterino. Exceto pela necessidade de curetagem, não houve complicações pós-aborto na maioria $(64 / 82,1 \%)$ das mulheres, porém $10(12,8 \%)$ delas também apresentaram infecção, $6(7,7 \%)$ receberam transfusão sanguínea e, em 2 (2,6\%), foi necessário realizar histerectomia.

A Tabela 1 mostra que houve maior concentração de mulheres na faixa dos 20 aos 24 anos $(69,2 \%)$, solteiras $(85,9 \%)$, pretas $(53,8 \%)$ e procedentes de Teresina (61,5\%). A maioria delas (59\%) tinha escolaridade correspondente ao ensino fundamental, e somente $6,4 \%$ relataram ter 
Tabela 1. Características sociodemográficas, reprodutivas e

gestacionais de mulheres com aborto provocado. Teresina, Brasil, 2013.

\begin{tabular}{|c|c|c|}
\hline Características & $\mathbf{n}$ & $\%$ \\
\hline \multicolumn{3}{|l|}{ Faixa etária (anos) } \\
\hline $18-19$ & 8 & 10,3 \\
\hline $20-24$ & 54 & 69,2 \\
\hline $25-29$ & 10 & 12,8 \\
\hline $30-34$ & 4 & 5,1 \\
\hline $35-39$ & 2 & 2,6 \\
\hline \multicolumn{3}{|l|}{ Escolaridade } \\
\hline Ensino fundamental & 46 & 59 \\
\hline Ensino médio & 27 & 34,6 \\
\hline Ensino superior & 5 & 6,4 \\
\hline \multicolumn{3}{|l|}{ Cor } \\
\hline Branca & 14 & 18,0 \\
\hline Parda & 22 & 28,2 \\
\hline Preta & 42 & 53,8 \\
\hline \multicolumn{3}{|l|}{ Situação conjugal } \\
\hline Solteira & 67 & 85,9 \\
\hline Casada & 11 & 14,1 \\
\hline \multicolumn{3}{|l|}{ Procedência } \\
\hline Teresina & 48 & 61,5 \\
\hline Interior do estado & 30 & 38,5 \\
\hline \multicolumn{3}{|l|}{ Gestações anteriores } \\
\hline Nenhuma & 45 & 57,7 \\
\hline 1 & 16 & 20,5 \\
\hline 2 & 9 & 11,5 \\
\hline$\geq 3$ & 8 & 10,3 \\
\hline \multicolumn{3}{|l|}{ Abortos anteriores provocados } \\
\hline Nenhum & 61 & 78,2 \\
\hline 1 & 15 & 19,2 \\
\hline 3 & 2 & 2,6 \\
\hline \multicolumn{3}{|l|}{ Diagnóstico da gestação } \\
\hline Teste de farmácia/ $\beta$-hCG & 57 & 73,1 \\
\hline Ultrassonografia & 6 & 7,7 \\
\hline Sinais/sintomas & 15 & 19,2 \\
\hline \multicolumn{3}{|l|}{ Idade gestacional } \\
\hline Até 8 semanas & 18 & 23,1 \\
\hline 9-12 semanas & 48 & 61,5 \\
\hline$\geq 13$ semanas & 12 & 15,4 \\
\hline
\end{tabular}

curso superior. Mais da metade $(57,7 \%)$ estava grávida pela primeira vez e $10,3 \%$ já tinham estado três ou mais vezes. Algumas das mulheres que já tinham um filho afirmaram que esse fato foi importante para a decisão de abortar na segunda gravidez, além da condição financeira e da falta de apoio do parceiro.

A confirmação da gravidez foi feita por meio de teste de farmácia e/ou $\beta$-hCG sérico por
$73,1 \%$ das entrevistadas e por ultrassonografia transvaginal por apenas 6 mulheres $(7,7 \%)$. Para $19,2 \%$ das mulheres, o atraso menstrual e outros sintomas sugestivos de gestação foram suficientes para a decisão pelo aborto. A idade gestacional estimada pela última menstruação ou por ultrassonografia era de até oito semanas em $23,1 \%$ dos casos, de nove a doze semanas em $61,5 \%$ e superior a treze semanas em 15,4\%. Das mulheres entrevistadas, 19,2\% já tinham abortado anteriormente, sendo que duas delas tinham provocado três abortos (Tabela 1).

\section{Práticas e itinerários abortivos}

O misoprostol foi utilizado isoladamente por $89,7 \%$ (70) das mulheres, mas 7,7\% delas o combinaram a chás para induzir o aborto. Duas entrevistadas $(2,6 \%)$ relataram o uso de sonda uterina associado ao misoprostol. Todas as mulheres que ingeriram chás e/ou ervas também necessitaram do uso posterior do misoprostol para interromper a gravidez. Os chás e as ervas variaram desde uma multimistura de ervas ("garrafada”) até chá de boldo, canela e buchinha. Daquelas que abortaram com misoprostol, 69,2\% (54) usaram quatro comprimidos, majoritariamente em dose única e à noite. Somente três mulheres fracionaram a ingestão do misoprostol em duas tomadas, fazendo uso de 10 comprimidos. Das entrevistadas, 74,4\% (58) usaram o misoprostol por via oral e vaginal simultaneamente, $14,1 \%$ (11) somente por via vaginal, e 11,5\% (9), exclusivamente por via oral (Tabela 2).

A Pesquisa Nacional do Aborto (PNA-entrevistas), publicada em 2012, entrevistou $122 \mathrm{mu}$ lheres de cinco capitais brasileiras e evidenciou que o principal método empregado por elas para interromper a gravidez foi uma combinação de misoprostol e chás, com finalização em hospital $^{10}$. Em outros estudos, as mulheres disseram que a opção pelo uso do misoprostol, comparado com outros métodos, tinha se dado em razão de sua disponibilidade imediata, facilidade de uso, preço mais acessível e segurança, além do efeito semelhante à indução de uma menstruação ${ }^{7,17,23}$. Nos primeiros anos de comercialização do misoprostol, as doses utilizadas pelas mulheres variaram consideravelmente, uma vez que os balconistas de farmácia, os médicos e as próprias mulheres não conheciam a melhor dose ou via de administração. Após algum tempo, seja pela maior experiência das mulheres, seja pelo preço mais caro do medicamento no mercado clandestino, a quantidade mais comum de comprimidos 
Tabela 2. Métodos e itinerários para o aborto provocado. Teresina, Brasil, 2013.

\begin{tabular}{lrr}
\hline \multicolumn{1}{c}{ Características } & n & $\%$ \\
\hline Métodos usados para abortar & & \\
$\quad$ Misoprostol isolado & 70 & 89,7 \\
$\quad$ Misoprostol + chás/ervas & 6 & 7,7 \\
$\quad$ Misoprostol + sondas & 2 & 2,6 \\
Via de administração do misoprostol & & \\
Oral + vaginal & 58 & 74,4 \\
Vaginal & 11 & 14,1 \\
Oral & 9 & 11,5 \\
Número de comprimidos utilizados & & \\
4 & 54 & 69,2 \\
5 & 6 & 7,7 \\
6 & 15 & 19,2 \\
10 & 3 & 3,9 \\
Local de compra do método abortivo & & \\
Farmácia & 56 & 71,8 \\
Residência/feira & 6 & 7,7 \\
Ignorado & 16 & 20,5 \\
Compra do método & & \\
Própria mulher & 36 & 46,2 \\
Namorado/marido & 22 & 28,2 \\
Amiga & 16 & 20,5 \\
Mãe & 4 & 5,1 \\
Acompanhante no serviço de saúde & & \\
Sozinha & 12 & 15,4 \\
Namorado/marido & 23 & 29,5 \\
Amiga & 30 & 38,5 \\
Mãe & 13 & 16,6 \\
\hline
\end{tabular}

era quatro. Os relatos mais frequentes foram dois comprimidos administrados por via oral e dois por via vaginal7 10,24,25.

O local de aquisição mais comum do misoprostol, geralmente pela própria mulher $(46,2 \%)$, foi a farmácia do bairro onde viviam $(71,8 \%)$. O companheiro e/ou marido adquiriu o medicamento para $28,2 \%$ das mulheres. As mulheres que usaram chás obtiveram o produto nas residências de especialistas em ervas ou compraram estas em mercados e feiras. As informações sobre a forma de uso do misoprostol foram fornecidas por amigas, irmãs ou outras mulheres a 75,6\% das entrevistadas (Tabela 2). Sem poder contar com a orientação de médicos e outros profissionais de saúde, as mulheres foram instruídas sobre doses e rotinas de uso do misoprostol pelos vendedores do medicamento, que frequentemente assumiram importante papel na trajetória de aborto. Apesar da ilegalidade, a maioria das mulheres compartilhou com outras pessoas o itinerário do aborto. $\mathrm{Na}$ aquisição da medicação ou na ida ao hospital, elas geralmente contaram com a ajuda de outras mulheres e também de seus parceiros. Somente 12 mulheres foram sozinhas ao hospital. No entanto, a espera pelo efeito do misoprostol foi narrada como um momento solitário, geralmente durante a madrugada, para não levantar suspeitas. As razões apontadas por elas para a procura do hospital oscilaram entre sangramento vaginal volumoso, cólicas uterinas intensas e medo de permanecer sozinha durante o processo, um dado semelhante ao descrito em estudos anteriores ${ }^{7,10,24-26}$.

\section{Maus-tratos e discriminação na assistência ao aborto}

A Tabela 3 evidencia que desrespeito e abuso durante a internação apareceram na narrativa de 26 mulheres, ou seja, uma em cada três mulheres entrevistadas sofreu alguma forma de violência institucional durante a hospitalização. Das categorias utilizadas para caracterizar violência institucional somente a detenção não foi observada. Foram reveladas práticas discriminatórias (como julgamento moral), tratamento não digno (ameaças de denúncia à polícia, uso de linguagem ríspida e grosseira e internação conjunta com puérperas), negligência (longa espera para realização do esvaziamento uterino), ausência de consentimento (procedimentos médicos realizados sem explicação), além de violação da privacidade e confidencialidade (entrevista e exame físico realizados com outras pacientes). Houve sobreposição de categorias de violência em 11 relatos, sendo a mais comum a associação de julgamento moral e longa espera para a curetagem. O itinerário de julgamento moral e/ou ameaças de denúncia à autoridade policial foi majoritariamente concentrado em todas as mulheres (17) que confessaram a indução do aborto à equipe de saúde. Por outro lado, mesmo entre as 44 mulheres que consideraram seu tratamento "bom" ou "dentro dos conformes", em 13 casos foram descritas formas de assistência à saúde que podem ser caracterizadas como discriminatórias.

$\mathrm{O}$ atendimento inicial é descrito como um momento tenso e de muito medo pelas mulheres, inclusive pela possibilidade de "descobrirem o comprimido na vagina”. Em outros estudos, as mulheres disseram que foram desestimuladas pelo vendedor do misoprostol a procurar os serviços de saúde, para não permitir a identificação do comprimido pelo profissional que as 
Tabela 3. Categorias e tipos de maus-tratos relatados pelas mulheres durante assistência ao aborto provocado. Teresina, Brasil, 2013.

\begin{tabular}{lcc}
\multicolumn{1}{c}{ Categorias/tipos } & $\mathbf{n}$ & $\%$ \\
\hline Todas as categorias & 26 & 33,3 \\
Discriminação & & 30,7 \\
$\quad$ Julgamento moral pela prática do aborto & 24 & 28,2 \\
Negligência & & 22,6 \\
$\quad$ Longa espera para realização da curetagem uterina & 20 & 28,2 \\
$\quad$ Ausência de acompanhante durante espera pela curetagem & & 23,1 \\
Cuidado clínico não digno & 22 & 15,4 \\
$\quad$ Ameaças de denúncia à polícia & 18 & 26,9 \\
Uso de linguagem ríspida e grosseira & 12 & 15,4 \\
$\quad$ Repreensão/gritos & & 15,4 \\
Ausência de confidencialidade/privacidade & 21 & 12 \\
Internação conjunta com puérperas & 12 & 25,6 \\
Entrevista e exame físico realizados com outras pacientes & & \\
Divulgação da história médica sem consentimento & 20 & 12,8 \\
Violência física & & 5,1 \\
Ausência de controle da dor/recusa em ofertar analgésicos & 10 & 1,3 \\
Cuidado clínico não consentido & 4 & 1 \\
Toque vaginal realizado sem explicação prévia & & \\
Transfusão sanguínea sem explicação prévia & & \\
Histerectomia sem explicação prévia & & 22 \\
\hline
\end{tabular}

atendesse $\mathrm{e}^{25,26}$. A descoberta do comprimido ou de seus resquícios na vagina foi o deflagrador mais comum da agressão verbal, na forma de intimidação, humilhação ou ameaça: eu esperei quieta o que pude, mas ainda tinha Citotec [na vagina]. Ai o doutor disse pra minha mãe que aquilo era a prova do crime e ele ia ser bonzinho e não anotar nada para eu não ser levada presa. Mesmo quando a violência não foi explicitada por atos verbais, houve julgamento moral, expresso em atitudes sutis de reprovação pelo olhar ou sorriso, principalmente quando existiam outros profissionais presentes.

Grande parte das mulheres descreveu que foram pressionadas pelos médicos a declarar a prática do aborto e, em alguns casos, chamadas de "mentirosas" quando insistiram que se tratava de aborto espontâneo. No entanto, mesmo quando confessou a prática, uma delas relatou que o profissional de saúde disse que ela devia se arrepender pelo pecado que tinha cometido e orar muito. O comportamento desrespeitoso e violento dos profissionais de saúde foi entendido por algumas mulheres como "necessário" e com "boa intenção", uma vez que os médicos e enfermeiras às vezes podem ser brutos e gritar, mas sempre querem o bem do paciente. Essa naturalização da violência institucional, encarada pelas mulheres e também por profissionais de saúde como um exercício da autoridade biomédica para uma boa prática de saúde, também é descrita como comum na assistência ao parto e puerpério ${ }^{27}$.

As narrativas de ameaça de denúncia à polícia são perturbadoras, convertendo o cenário do serviço de saúde, que deveria ser acolhedor, em espaço de ameaça para as mulheres. Mesmo sem apresentar um padrão comum, essas histórias foram mais encontradas entre aquelas internadas com complicações mais graves, aquelas com idade gestacional mais avançada e também nas situações onde houve identificação do medicamento na vagina. A enunciação, pelos profissionais, de que as mulheres cometeram um "assassinato", um "crime" ou "um pecado contra a sociedade" foi descrita por elas como uma situação de intenso sofrimento: ele [o médico] me disse que eu podia sair algemada daqui e eu achei que minha vida ia acabar se isso acontecesse. Internada por quinze dias após ter sido submetida a uma histerectomia por aborto infectado, uma das mulheres confessou à equipe de saúde que utilizou misoprostol e sonda vaginal. Segundo seu relato, ela abortou 
ainda na admissão no hospital e uma enfermeira disse que agora eu ia ter que prestar contas era com o delegado. Além da reiterada ameaça de denúncia à polícia, ela ouviu o médico dizer que todo ano era assim: bastava esperar dois, três meses depois do carnaval pra maternidade ficar cheia dessas mulheres que abortavam....

Uma pesquisa conduzida no Distrito Federal que analisou dez processos que chegaram ao Ministério Público em razão do comércio ou uso ilegal do misoprostol demonstrou que, das sete mulheres indiciadas, três foram denunciadas pela equipe de saúde após chegarem ao hospital público para finalização do aborto ${ }^{26}$. Ainda que a denúncia em si não tenha ocorrido entre as mulheres entrevistadas neste estudo, o anúncio da ameaça já abala o acordo básico de confiança depositada por elas nos profissionais e no sistema de saúde. A quebra desse acordo é refutada por vários códigos deontológicos na área da saúde e pela política pública ${ }^{28}$. O Código de Ética Médica, por exemplo, estabelece, no capítulo referente ao sigilo profissional, que é vedado ao médico "revelar fato de que tenha conhecimento em virtude do exercício de sua profissão, salvo por justa causa, dever legal ou autorização expressa do paciente" ${ }^{29}$. Nenhuma dessas exceções, porém, se aplicaria ao caso do aborto autoprovocado. O sigilo é um dos mais importantes pilares da relação médico-paciente e de outros profissionais, o que faz com que as pessoas não temam ocultar fatos significativos para a resolução de seu problema de saúde.

Constrangimento e pouca privacidade também caracterizaram a admissão das mulheres no hospital. Grande parte delas informou que a mesma entrevista era realizada por profissionais diferentes e, ao final, o caso era discutido na frente de todo mundo. As queixas relacionadas ao exame físico se estendiam desde a ausência de vestimenta adequada até a grande quantidade de manipulações genitais. Uma mulher que nunca tinha realizado exame ginecológico descreveu sua impressão da admissão: eu me senti a pior das mulheres naquela situação. Ele [o médico] foi logo enfiando o dedo na vagina, bem no fundo, sem nem me dizer nada. Só me disse que ia fazer o toque, mas eu não sabia como era. Depois veio outro doutor e fez de novo. Eu comecei a chorar e ele me disse que era pra eu me acalmar, porque quem era culpada era eu, que tinha feito o aborto. Mas precisava assim? Ser assim?.

Após a internação, o cenário é rotulado como mais tranquilo, exceto pela longa espera pela curetagem. Como regra geral, as participantes aguardaram "bastante tempo", "algumas horas", "o dia todo", mesmo que estivessem sangrando ou com dor. Após esperar por mais de 12 horas sentada em uma cadeira na antessala do centro cirúrgico onde seria realizada a curetagem uterina, uma mulher questionou sobre a demora do procedimento. Segundo ela, a enfermeira disse que a prioridade aqui é para mulher que vai ter bebê. Mulher que quer tirar o seu [bebê] tem que aprender a esperar a sua vez. No Brasil, é recorrente a narrativa de longa espera pelo atendimento em casos de aborto, com frequente adiamento da curetagem uterina para o final do expediente de trabalho dos médicos ${ }^{10,20-22}$. Apesar de não se saber se essa demora acontece por discriminação contra a mulher por ter realizado um aborto, existem evidências que demonstram que o atraso em realizar o procedimento adequado para esvaziamento uterino aumenta as chances de complicações $^{30-32}$.

Durante a espera pela curetagem uterina, a informação de dor nem sempre foi suficiente para que a equipe de saúde ofertasse métodos farmacológicos para seu controle. Quase todas as mulheres disseram que experimentaram dor antes do procedimento, e somente 12 receberam algum tipo de analgésico. A justificativa para a não oferta de medicamentos, quando houve, variou desde a informação de que tinha que ter dor pra eliminar tudo que tinha ficado dentro do útero até a declaração de que não tenho tempo agora porque tem muita mulher parindo e isso é mais urgente. A experiência da dor persistente, aliada ao sangramento e à longa espera, fez com que uma das entrevistadas classificasse o atendimento como horrível e parecido com o inferno. E prosseguiu: pra mim, o que era mais importante era que alguém me ouvisse, me explicasse o que estava acontecendo. Eu só queria um remédio para aliviar [a dor] e alguém que me acalmasse. Mas não teve. Sob a visão de algumas mulheres, ao não minimizarem a dor, os profissionais de saúde querem é mesmo castigar pelo aborto provocado: ela [a médica] falou que eu não podia ficar gritando e, se eu não quisesse ter dor, que eu tivesse pensado antes.

Expresso em normas nacionais e internacionais, o controle e manejo da dor no processo de abortamento, seja ele provocado ou não, é parte fundamental da assistência em saúde ${ }^{28,33}$. A recusa em ofertar analgésicos é um claro desrespeito aos direitos humanos básicos das mulheres e pode ser encarada como tratamento desumano e degradante. A crença de que as mulheres que provocaram aborto deveriam ser punidas está entre as principais razões para o inadequado ma- 
nejo da dor. Além disso, muitos profissionais de saúde acreditam que o controle medicamentoso da dor não seria necessário nessa situação ${ }^{34}$. No entanto, existem recomendações internacionais para que o uso de analgésicos seja sistemático antes de qualquer procedimento, exceto em condições excepcionais.

Vale observar ainda que a aspiração manual intrauterina (AMIU) deveria ser o método escolhido para tratar grande parte de casos de aborto incompleto. Uma das vantagens da AMIU, quando comparada à curetagem uterina, é a menor necessidade de controle da dor, principalmente quando associada com orientação e aconselhamento prévios ao procedimento. Por ser segura, mais barata e tão efetiva quanto a curetagem, a AMIU tem sido defendida como o procedimento de eleição para esvaziamento uterino, sempre que possível ${ }^{33}$.

Apesar do alívio físico e emocional após a curetagem uterina, muitas mulheres narraram o desconforto pela internação em unidades conjuntas com puérperas e seus recém-nascidos. "Mal-estar emocional", "tristeza", "constrangimento", "frustração" e "piora do sentimento de culpa" foram declarações comuns. Argumentouse por um "local mais adequado" de internação entre a maioria das mulheres, mesmo entre aquelas que julgaram seu atendimento como satisfatório. O "choro dos bebês", o "ambiente de alegria da família" e a "visão da amamentação" foram razões apontadas por elas como suficientes para reivindicar espaços próprios para o atendimento pós-aborto. No entanto, poucas maternidades e hospitais públicos brasileiros contam com enfermarias específicas para o cuidado de mulheres que abortam ${ }^{19}$. A ausência de espaços separados para atender as especificidades de mulheres pós -aborto pode significar mais uma forma de discriminação, punição e violência institucional.

\section{Considerações finais}

Os dados desta pesquisa evidenciam que a violência institucional na assistência ao aborto provocado parece não ser um fenômeno fortuito. As narrativas das mulheres mostraram que as manifestações da violência ocorreram tanto na relação estrutural com o serviço (como a falta de estrutura para oferecer privacidade e acomodação adequadas) ou relacionadas ao comportamento dos profissionais de saúde (como as ameaças, jul- gamento moral e discriminação dirigidas às mulheres que declararam indução do aborto). Para o exercício do direito à saúde, há necessidade que as mulheres tenham serviços de saúde acessíveis, disponíveis e de boa qualidade, incluindo profissionais capacitados e capazes de compreender suas demandas.

A ausência de critérios uniformes de definição dificulta a mensuração da prevalência de maus-tratos durante assistência em saúde ${ }^{11,12}$. Dada a escassez de estudos nacionais e internacionais desenhados com o objetivo de caracterizar a violência institucional durante tratamento do aborto provocado, os dados deste artigo ganham destaque por atestar a alta frequência do fenômeno e, possivelmente, chamar a atenção de profissionais de saúde e legisladores. Por outro lado, os resultados apresentados se referem a um estudo local e, portanto, não podem ser generalizados. Não se sabe se situações semelhantes são encontradas em outros serviços, mas é possível que o ambiente de controvérsia moral do aborto no país favoreça a violência institucional na assistência às complicações dessa prática. Estudos futuros, de abrangência nacional, poderão esclarecer a real magnitude dos maus-tratos contra as mulheres durante a assistência ao aborto provocado.

A legislação nacional para a assistência ao aborto estabelece que o cuidado deve ser pautado por acolhimento, informação, orientação e suporte emocional, independentemente das crenças da equipe de saúde ${ }^{28}$. As experiências de maus-tratos e discriminação podem ter impacto sobre a saúde global da mulher e violam seu direito ao atendimento digno, respeitoso e baseado na melhor evidência científica para tratamento das complicações do aborto provocado. Além disso, espelham a crise do sistema de saúde, que, apesar da existência de uma política pública voltada para o atendimento humanizado ao aborto, não atende as necessidades das mulheres com equidade, um dos princípios fundamentais da assistência à saúde no Brasil. Se considerarmos que o problema da violência institucional é multifatorial, as intervenções para eliminá-la necessitam atuar em diversos níveis. O aprimoramento da política pública existente, a melhor estruturação dos serviços de saúde, além do continuado treinamento e a sensibilização de profissionais de saúde para a violência de gênero, devem ser encarados como etapas significativas na melhoria da assistência às complicações do aborto provocado. 


\section{Colaboradores}

AP Madeiro participou da concepção do projeto de pesquisa, do levantamento e análise dos dados, da redação do artigo e da aprovação da versão final. AC Rufino colaborou no projeto de pesquisa, na coleta e análise dos dados, na redação e na aprovação da versão final.

\section{Referências}

1. World Health Organization (WHO). Unsafe abortion: Global and regional estimates of the incidence of unsafe abortion and associated mortality in 2008. $6^{\text {th }} \mathrm{ed}$. Geneva: WHO; 2011.

2. Sedgh G, Singh S, Shah IH, Ahman E, Henshaw SK, Bankole A. Induced abortion: incidence and trends worldwide from 1995 to 2008. Lancet 2012; 379(9816):625-632.

3. Adler AJ, Filippi V, Thomas SL, Ronsmans C. Quantifying the global burden of morbidity due to unsafe abortion: magnitude in hospital-based studies and methodological issues. Int J Obstet Gynecol 2012; 118(Supl. 2):S65-77.

4. Dragoman M, Sheldon WR, Qureshi Z, Blum J, Winikoff B, Ganatra B, on behalf of the WHO Multicountry Survey on Maternal Newborn Health Research Network. Overview of abortion cases with severe maternal outcomes in the WHO Multicountry Survey on Maternal and Newborn Health: a descriptive analysis. BJOG 2014; 121(Supl. 1):25-31.

5. Diniz D, Medeiros M. Pesquisa Nacional de Aborto: um estudo com técnica de urna. Cien Saude Coletiva 2010; 15(Supl. 1):S959-S966.

6. Arilha M, Barbosa RM. Cytotec in Brazil: "at least it doesn't kill”. Reprod Health Matters 1993; 1(2):41-52.

7. Blanchard K, Clark S, Winikoff B, Gaines G, Kabani G, Shannon C. Misoprostol for women's health. Obstet Gynecol 2002; 99(2):316-332.

8. Singh S, Monteiro MFG, Levin J. Trends in hospitalization for abortion-related complications in Brazil, 19922009: why the decline in numbers and severity? Int $J$ Gynecol Obstet 2012; 118(Supl. 2):S99-S106.

9. Diniz D, Castro R. O comércio de medicamentos de gênero na mídia impressa brasileira: misoprostol e mulheres. Cad Saude Publica 2011; 27(1):94-102.

10. Diniz D, Medeiros M. Itinerários e métodos do aborto ilegal em cinco capitais brasileiras. Cien Saude Coletiva 2012; 17(7):1671-1681.

11. Bowser D, Hill K. Exploring evidence for disrespect and abuse in facility-based childbirth: report of a landscape analysis. Maryland: USAID/TRAction Project; 2010.

12. Bohren MA, Vogel JP, Hunter EC, Lutsiv O, Makh SK, Souza JP, Aguiar C, Coneglian FS, Diniz ALA, Tunçalp O, Javadi D, Oladapo OT, Khosla R, Hindin MJ, Gulmezoglu AM. The mistreatment of women during childbirth in health facilities globally: a mixed-methods systematic review. PLoS Med 2015; 12(6):e1001847.

13. d'Oliveira AFPL, Diniz SG, Schraiber LB. Violence against women in health-care institutions: an emerging problem. Lancet 2002; 359(9318):1681-1685.

14. Gomes AMA, Nations MK, Luz MT. Pisada como pano de chão: experiência de violência hospitalar no Nordeste brasileiro. Saude Soc 2008; 17(1):61-72.

15. Diniz SG, d'Oliveira AFPL, Lansky S. Equity and women's health services for contraception, abortion and childbirth. Reprod Health Matters 2012; 20(40):94-101.

16. Brasil. Ministério da Saúde (MS). Violência intrafamiliar: orientações para prática em serviço. Brasília: MS; 2001.

17. Zamberlin N, Romero M, Ramos S. Latin American women's experiences with medical abortion in settings where abortion is legally restricted. Reprod Health 2012; 9(1):34. 
18. Fundação Perseu Abramo. Mulheres brasileiras e gênero nos espaços público e privado. 2010. [acessado 2014 dez 7]. Disponível em: http://www.fpabramo.org.br/ sites/default/files/pesquisaintegra.pdf.

19. Aquino EML, Menezes G, Barreto-de-Araújo TV, Alves SV, Almeida MCC, Schiavo E, Lima LP, Menezes CAS, Marinho LFB, Coimbra LC, Campbell O. Qualidade de atenção ao aborto no Sistema Único de Saúde do Nordeste brasileiro: o que dizem as mulheres? Cien Saude Colet 2012; 17(7):1765-1776.

20. Bertolani GMB, Oliveira EM. Mulheres em situação de abortamento: estudo de caso. Saude Soc 2010; 19(2):286-301.

21. Motta IS. A relação interpessoal entre profissionais de saúde e a mulher em abortamento incompleto: "o olhar da mulher". Rev Bras Saude Matern Infantil 2005; 5(2):219-228.

22. Galli B, Drezett J, Adesse L. Dilemas e soluções nos serviços de saúde: um estudo de casos na atenção ao abortamento com foco nos direitos humanos das mulheres. Rio de Janeiro: Ipas Brasil; 2007.

23. Nations MK, Misago C, Fonseca W, Correia LL, Campbell OMR. Women's hidden transcripts about abortion in Brazil. Soc Sci Med 1997; 44(12):1833-1845.

24. Costa SH, Vessey MP. Misoprostol and illegal abortion in Rio de Janeiro, Brazil. Lancet 1993; 341(8855):12581261.

25. Coelho HL, Teixeira AC, Cruz MF, Gonzaga SL, Arrais PS, Luchini L, La Vecchia C, Tognoni G. Misoprostol: the experience of women in Fortaleza, Brazil. Contraception 1994; 49(2):101-110.

26. Diniz D, Madeiro A. Cytotec e aborto: a polícia, os vendedores e as mulheres. Cien Saude Colet 2012; 17(7):1795-1804.

27. Aguiar JM, d'Oliveira AFPL, Schraiber LB. Violência institucional, autoridade médica e poder nas maternidades sob a ótica dos profissionais de saúde. Cad Saude Publica 2013; 29(11):2287-2296.
28. Brasil. Ministério da Saúde (MS). Atenção humanizada ao abortamento: norma técnica. $2^{\text {a }}$ ed. Brasília: MS; 2010.

29. Conselho Federal de Medicina. Código de Ética Médica [internet]. Brasília; 2009 [acessado 2014 dez 7]. Disponível em: http://www.cremers.org.br/pdf/codigodeetica/codigo_etica.pdf.

30. Steele J, Chiarotti S. With everything exposed: cruelty in post-abortion care in Rosario, Argentina. Reprod Heath Matters 2004; 14(Supl. 24):39-46.

31. Mayi-Tsonga S, Oksana L, Ndombi I, Diallo T, Sousa $\mathrm{MH}$, Faúndes A. Delay in the provision of adequate care to women who died from abortion-related complications in the principal maternity hospital of Gabon. Reprod Health Matters 2009; 17(34):65-70.

32. Ziraba AK, Izugbara C, Levandowski BA, Gebreselassie H, Mutua M, Mohamed SF, Egesa C, Kimani-Murage E. Unsafe abortion in Kenya: a cross-sectional study of abortion complication severity and associated factors. BMC Pregnancy Childbirth 2015; 15:34.

33. Organização Mundial da Saúde (OMS). Abortamento seguro: orientação técnica e política para os sistemas de saúde. 2a ed. Genebra: OMS; 2013.

34. Solo J. Easing the pain: pain management in the treatment of incomplete abortion. Reprod Health Matters 2000; 8(15):45-51.

Artigo apresentado em 27/11/2015

Aprovado em 25/03/2016

Versão final apresentada em 27/03/2016 